Research Paper

\title{
Circulating exosomal microRNA-203 is associated with metastasis possibly via inducing tumor-associated macrophages in colorectal cancer
}

\author{
Yuki Takano ${ }^{1,2, *}$, Takaaki Masuda ${ }^{1, *}$, Hisae Iinuma ${ }^{3}$, Rui Yamaguchi ${ }^{4}$, Kuniaki Sato ${ }^{1}$, \\ Taro Tobo ${ }^{5}$, Hidenari Hirata ${ }^{1}$, Yosuke Kuroda ${ }^{1}$, Sho Nambara ${ }^{1}$, Naoki Hayashi ${ }^{1}$, \\ Tomohiro Iguchi ${ }^{1}$, Shuhei Ito ${ }^{1}$, Hidetoshi Eguchi ${ }^{1}$, Takahiro Ochiya ${ }^{6}$, Katsuhiko \\ Yanaga $^{2}$, Satoru Miyano ${ }^{4}$ and Koshi Mimori ${ }^{1}$ \\ ${ }^{1}$ Department of Surgery, Kyushu University Beppu Hospital, Beppu, Japan \\ ${ }^{2}$ Department of Surgery, Jikei University School of Medicine, Tokyo, Japan \\ ${ }^{3}$ Department of Surgery, Teikyo University, Tokyo, Japan \\ ${ }^{4}$ Human Genome Center, Institute of Medical Science, University of Tokyo, Tokyo, Japan \\ ${ }^{5}$ Department of Pathology, Kyushu University Beppu Hospital, Beppu, Japan \\ ${ }^{6}$ Division of Molecular and Cellular Medicine, National Cancer Center Research Institute, Tokyo, Japan \\ "These authors have contributed equally to this work \\ Correspondence to: Koshi Mimori, email: kmimori@beppu.kyushu-u.ac.jp \\ Keywords: miR-203, exosome, tumor-host interaction, tumor-associated macrophage, colorectal cancer \\ Received: March 06, $2017 \quad$ Accepted: June 26, $2017 \quad$ Published: August 07, 2017 \\ Copyright: Takano et al. This is an open-access article distributed under the terms of the Creative Commons Attribution License \\ 3.0 (CC BY 3.0), which permits unrestricted use, distribution, and reproduction in any medium, provided the original author and \\ source are credited.
}

\section{ABSTRACT}

A primary tumor can create a premetastatic niche in distant organs to facilitate the development of metastasis. The mechanism by which tumor cells communicate with host cells to develop premetastatic niches is unclear. We focused on the role of microRNA (miR) signaling in promoting metastasis. Here, we identified miR-203 as a signaling molecule between tumors and monocytes in metastatic colorectal cancer (CRC) patients. Notably, high expression of serum exosomal miR-203, a major form in circulation, was associated with distant metastasis and an independent poor prognostic factor, whereas low expression in tumor tissues was a poor prognostic factor in CRC patients. We also found that exosomes carrying miR-203 from CRC cells were incorporated into monocytes and miR-203 could promote the expression of M2 markers in vitro, suggesting miR-203 promoted the differentiation of monocytes to M2-tumor-associated macrophages (TAMs). In a xenograft mouse model, miR-203transfected CRC cells developed more liver metastasis compared to control cells. In conclusion, serum exosomal miR-203 expression is a novel biomarker for predicting metastasis, possibly via promoting the differentiation of monocytes to M2-TAMs in CRC. Furthermore, we propose the concept of site-dependent functions for miR-203 in tumor progression.

\section{INTRODUCTION}

Distant metastasis is the leading cause of mortality in cancer patients, including those with CRC which is one of the most common malignant tumors worldwide
[1] and has a poor prognosis despite recent advances in diagnosis and treatment [2]. Metastasis is a multistep process that requires tumor cells to leave the primary tumor through intravasation, survival in the circulation and extravasation into distant organs that provide an appropriate microenvironment. 
The 'seed and soil hypothesis' of malignancy proposed that the distribution of metastasis from cancers is not based on chance alone, and that the microenvironment of the potential metastatic 'soil' could either promote or prevent the primary 'seed' from growing [3, 4]. This "seed and soil" hypothesis is fundamental to the concept of the premetastatic niche whereby tumors prepare defined organs for metastasized cells [5]. It is now well recognized that the formation of a premetastatic niche is crucial for the development of metastasis.

We recently reported that increased production of $\mathrm{C}-\mathrm{C}$ motif chemokine 2 (CCL2) due to downregulation of F-box and WD repeat domain containing 7 ( $F B X W 7$ ) in bone marrow (BM)-derived stromal cells promoted the formation of premetastatic niches through recruitment of myelo-monocytic cell-derived suppressor cells and TAMs, thereby promoting metastatic tumor growth [6]. Our finding provided strong evidence that host cells play a critical role in tumor metastasis through the formation of premetastatic niches. However, the mechanisms by which tumor cells communicate with the host cells to develop a premetastatic niche are poorly understood. Understanding this mechanism should open up a new field of cancer therapy through the targeting of tumorhost interaction.

We have focused on circulating miRs, a class of small noncoding RNAs that are mainly carried by exosomes in circulation [7]. They may act as critical intercellular signals between cancer cells and host BM cells, promoting the development of premetastatic niches. Substantial evidence suggests that miRs play an important role in multiple aspects of tumor progression [8] and can work as messengers in intracellular communication through extracellular vesicles such as exosomes [9]. miRs regulate one-third of all human protein-coding genes by binding to the 3 '-untranslated region of a target mRNA [10]. miRs affect a wide variety of biological processes, including proliferation, differentiation, cell fate determination, apoptosis, and cancer by mediating mRNA destabilization or translational repression. We previously determined the clinical significance of miR expression in peripheral blood and $\mathrm{BM}$, and identified a correlation between miRNA expression and distant metastasis [1114]. These studies provided clues as to the mechanism of communication between tumors and host cells, including TAMs in CRC.

In this study, we identified $m i R-203$ as a signaling molecule between tumor and host immune cells. Moreover, we assessed the clinical significance of $m i R-203$ expression in both exosomes in serum and tumor tissues in CRC patients. Next, we examined if miR-203 from tumor cells could promote distant metastasis by affecting host immune cells in vitro and in vivo. Finally, we propose that $m i R-203$ may have dual functions in CRC progression.

\section{RESULTS}

\section{An association between disseminated tumor cells (DTCs) and monocytes was shown by genes downstream from miR-203 in CRC patients with distant metastasis}

We used a MACS system to separate $C D 14^{+}$cells (monocytes) and $C D 14^{-} / C D 45^{-} / E p C A M^{+}$cells (DTCs) from BM of CRC patients with or without distant metastasis (Figure 1A). After extracting mRNAs, gene expression microarray analysis was performed on the monocytes and DTCs for each sample (Figure 1B).

For screening miRs that may have a significant role in the interaction between monocytes and DTCs in metastatic CRCs, we compared expression levels of mRNAs between monocytes and DTCs either within the group of CRC patients with metastasis (4 cases: metastasis group) or within the group of those without metastasis (6 cases: non-metastasis group) as follows. We searched miR-target gene sets in each of which the member genes were significantly enriched in genes whose expression levels were statistically different between in DTCs and monocytes within the metastasis group but not within the non-metastasis group. For that purpose, we analyzed mRNA expressions by gene set enrichment analysis (GSEA) software as described in MATERIALS AND METHODS.

As the result of the screening, we found $m i R-203$ as a candidate; the $m i R-203$ target gene set was negatively enriched in DTCs relative to monocytes $(P=0.025)$ within the metastasis group but not significant within the nonmetastasis group ( $P=0.245$ ) (Figure 1C). These data imply that miR-203 from DTCs could affect monocytes in BM during the process of metastasis.

\section{Clinical significance of exosomal $m i R-203$ expression in serum in CRC}

Based on GSEA data, we hypothesized that $m i R-203$ produced by cancer cells was associated with metastatic events through its regulatory linkage with host cells. In other words, we proposed that circulating miR-203 affected the formation of premetastatic niches, which is considered essential for tumor metastasis. To pursue this possibility, we examined the clinical significance of exosomal miR-203 in serum because it is a major fraction of $\mathrm{miR}$ in circulation and exosomes are considered an intercellular messenger [7, 15].

First, the expression of serum exosomal $m i R-203$ was analyzed in $240 \mathrm{CRC}$ patients. The values ranged from 0.01 to 8.48 (median, 3.89). The median expression levels of $m i R-203$ in each TNM stage were 1.96, 2.94, 4.09 and 5.71, respectively (Figure 2A). The level of $m i R-203$ expression was significantly upregulated in a TNM stage-dependent manner (Figure 2A). Next, we 
assessed the prognostic significance of serum exosomal miR-203 expression using all 240 cases for overall survival (OS) and 170 cases with Stages I, II and III with curative surgery for disease-free survival (DFS). Cases were divided into two groups as described in Materials and Methods. The cut-off value was 3.89. High exosomal miR-203 expression was significantly associated with poor DFS and OS $(P<0.01$, Figure $2 \mathrm{~B})$. Then, univariate and multivariate analyses for prognosis were performed (Table 1). Clinicopathological factors that were found to be prognostic factors in univariate analysis were included in the multivariate analysis. Notably, multivariate analysis demonstrated that exosomal miR-203 expression in serum was an independent prognostic factor for both DFS and OS in CRC patients. Moreover, we performed subgroup analyses for prognosis according to tumor stage. As shown in Figure 2C and 2D, the trends indicated that high expression group exhibited poorer prognosis. Statistically significant differences in DFS or OS were noted among only patients with an advanced stage: DFS, stage III $(P=0.01)$ or OS, stages III $(P<0.01)$ and IV $(P=0.03)$, respectively. In Figure $2 \mathrm{E}$, no statistical correlation of $m i R-203$ expression was shown between in serum exosomes and tumor tissues $\left(\mathrm{R}^{2}=0.10\right)$.

Next, the relationship between clinicopathological factors and exosomal miR-203 expression in serum was examined using the 240 patients. Compared with the low miR-203 expression group, the high expression group showed a higher incidence of venous invasion $(P=0.02)$, lymph node metastasis $(P<0.01)$, distant metastasis $(P<0.01)$ including liver metastasis $(P<0.01)$, lung metastasis $(P<0.05)$ and peritoneal dissemination
A

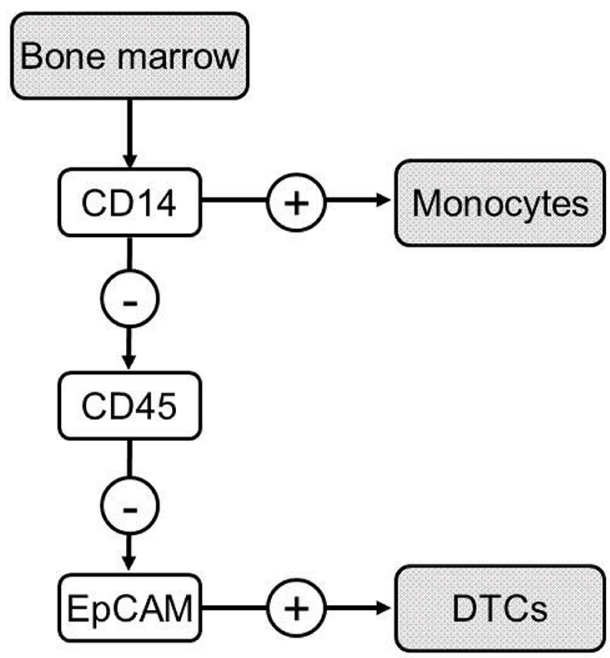

B

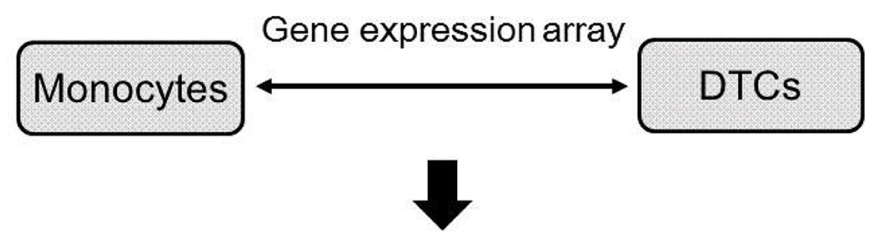

Identify microRNAs which have a role in the interaction between monocytes and DTCs in metastatic CRC

C

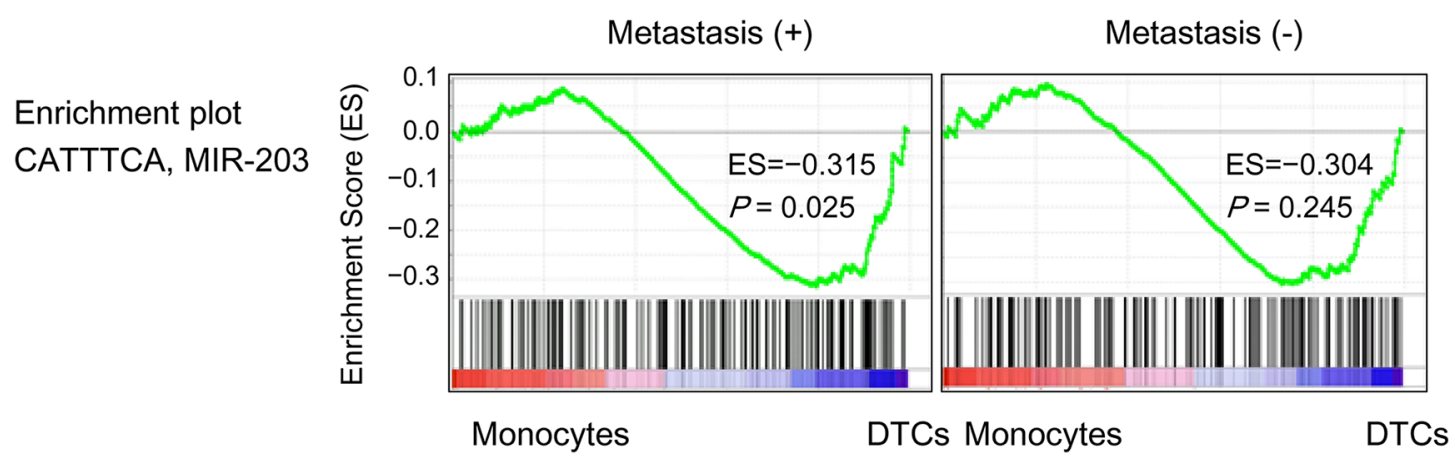

Figure 1: Identification of miR-203 as a potential intercellular signal between DTCs and monocytes. (A) Isolation of DTCs and monocytes from BM using MACS. (B) Gene expression array analysis identified genes that showed conflicting expression in DTCs and monocytes in metastatic CRC patients. (C) GSEA with DTCs and monocytes from CRC patients with or without metastasis was performed to identify upstream miRs for the genes that were identified by gene expression analysis (B). 
A

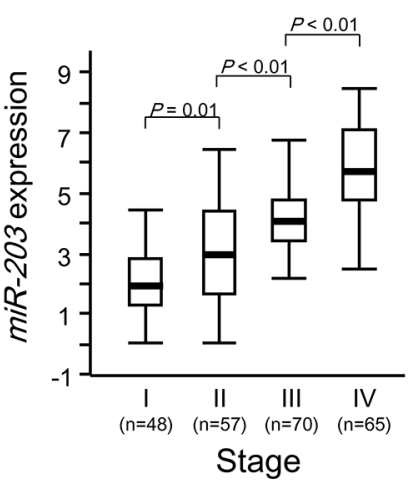

C

Stage

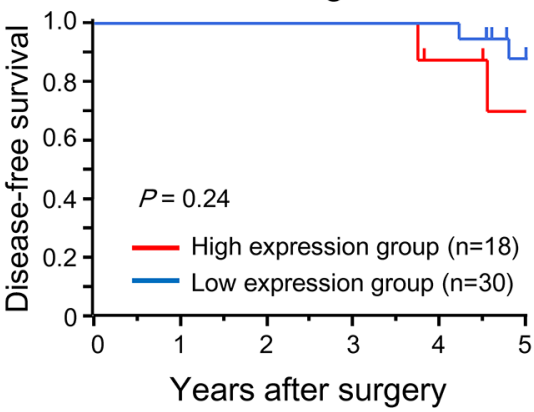

D

Stage I

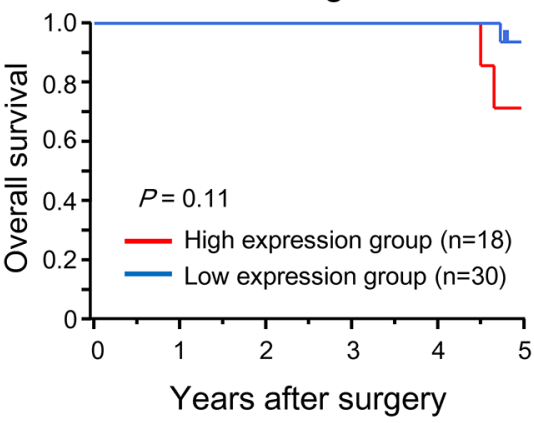

Stage IV

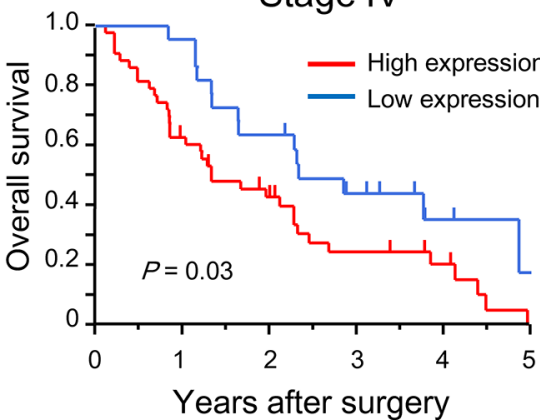

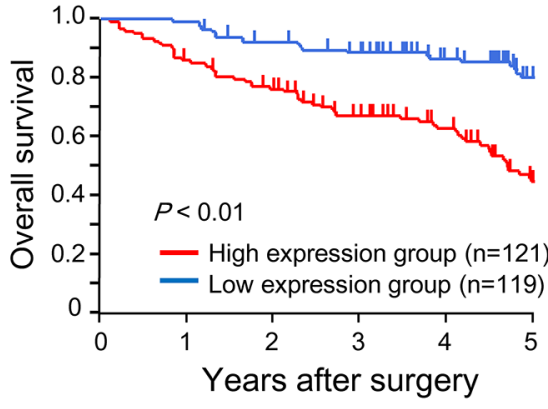

Stage III
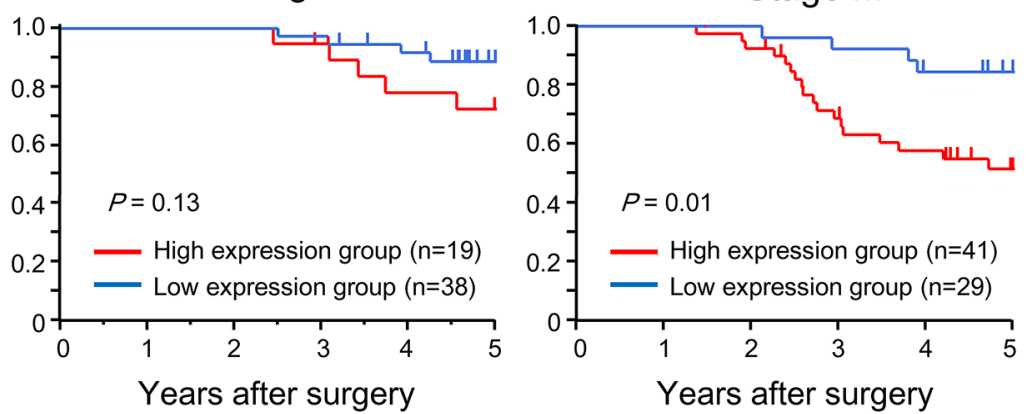

Stage II

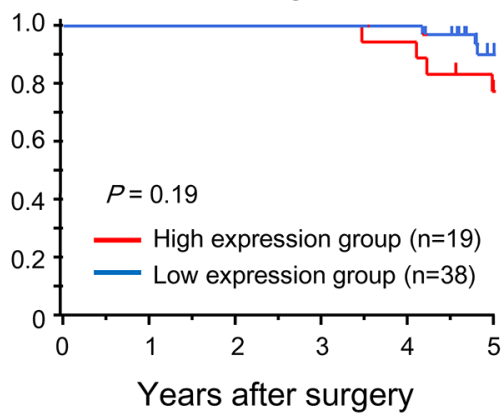

Stage III

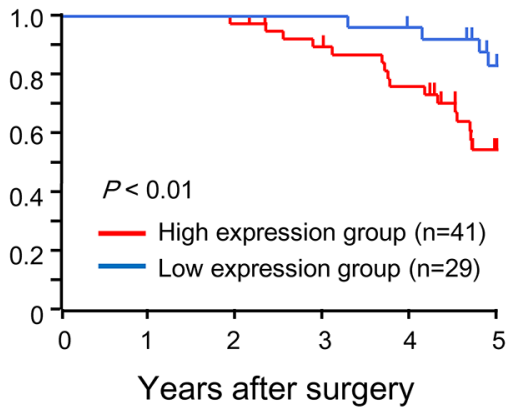

E

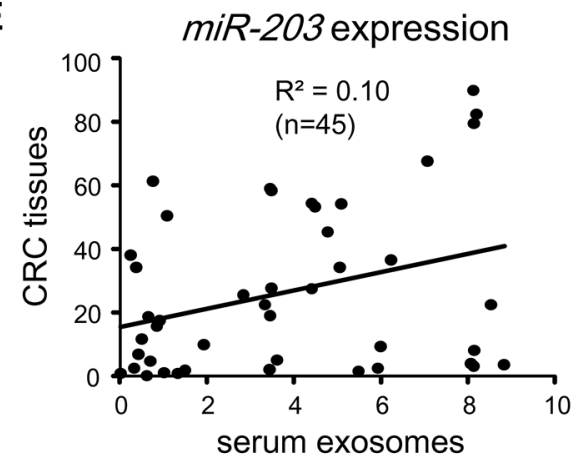

Figure 2: Prognostic significance of exosomal miR-203 expression in serum in CRC patients. (A) Exosomal miR-203 expression in serum in different TNM stages of CRC. (B) Kaplan-Meier survival curves of CRC patients according to miR-203 expression level. Left: DFS of patients who underwent curative surgery. Right: OS of all patients. (C) Subgroup analyses for DFS of patients with Stages I, II or III who underwent curative surgery according to tumor stage. (D) Subgroup analyses for OS of all patients according to tumor stage. (E) Correlation of miR-203 expression between in serum exosome and in CRC tissues. 
Table 1: Univariate and multivariate analysis of prognostic factors for OS and DFS of CRC patients

\begin{tabular}{|c|c|c|c|c|}
\hline \multirow[t]{2}{*}{ Variables } & \multicolumn{2}{|c|}{ Univariate analysis } & \multicolumn{2}{|c|}{ Multivariate analysis } \\
\hline & $\begin{array}{c}\text { HR } \\
\left(95 \% \mathrm{CI}^{\mathrm{a}}\right)\end{array}$ & $\boldsymbol{P}$ & $\begin{array}{c}\text { HR } \\
(95 \% \mathrm{CI})\end{array}$ & $P$ \\
\hline \multicolumn{5}{|l|}{$\begin{array}{l}\text { OS } \\
(n=240)\end{array}$} \\
\hline $\begin{array}{l}\text { Histology } \\
\text { (Not well/Well) }\end{array}$ & $\begin{array}{c}1.29 \\
(0.81-2.02)\end{array}$ & 0.28 & & \\
\hline $\begin{array}{l}\text { Tumor size } \\
(\geqq 5 \mathrm{~cm} /<5 \mathrm{~cm})\end{array}$ & $\begin{array}{c}1.59 \\
(1.01-2.50)\end{array}$ & 0.04 & $\begin{array}{c}1.22 \\
(0.76-1.97)\end{array}$ & 0.42 \\
\hline $\begin{array}{l}\text { Depth of invasion } \\
\left(\geqq \mathrm{SS}^{c} / \leqq \mathrm{MP}^{b}\right)\end{array}$ & $\begin{array}{c}2.58 \\
(1.47-4.91)\end{array}$ & $<0.01$ & $\begin{array}{c}1.10 \\
(0.54-2.37)\end{array}$ & 0.79 \\
\hline $\begin{array}{l}\text { Venous invasion } \\
(+/-)\end{array}$ & $\begin{array}{c}3.12 \\
(1.82-5.71)\end{array}$ & $<0.01$ & $\begin{array}{c}1.71 \\
(1.88-3.46)\end{array}$ & 0.11 \\
\hline $\begin{array}{l}\text { Lymphatic invasion } \\
(+/-)\end{array}$ & $\begin{array}{c}2.60 \\
(1.66-4.11)\end{array}$ & $<0.01$ & $\begin{array}{c}1.60 \\
(0.95-2.70)\end{array}$ & 0.08 \\
\hline $\begin{array}{l}\text { Lymph node metastasis } \\
(+/-)\end{array}$ & $\begin{array}{c}2.06 \\
(1.31-3.27)\end{array}$ & $<0.01$ & $\begin{array}{c}1.02 \\
(0.61-1.71)\end{array}$ & 0.94 \\
\hline $\begin{array}{l}\text { Liver matastasis } \\
(+/-)\end{array}$ & $\begin{array}{c}11.54 \\
(7.07-18.89)\end{array}$ & $<0.01$ & $\begin{array}{c}5.59 \\
(3.04-10.53)\end{array}$ & $<0.01$ \\
\hline $\begin{array}{l}\text { Peritoneal dissemination } \\
(+/-)\end{array}$ & $\begin{array}{c}3.11 \\
(1.37-6.18)\end{array}$ & $<0.01$ & $\begin{array}{c}2.79 \\
(1.16-5.97)\end{array}$ & 0.02 \\
\hline $\begin{array}{l}\text { Serum CEA } \\
(\geqq 5.0 \mathrm{ng} / \mathrm{ml} /<5.0 \mathrm{ng} / \mathrm{ml})\end{array}$ & $\begin{array}{c}4.56 \\
(2.78-7.79)\end{array}$ & $<0.01$ & $\begin{array}{c}1.97 \\
(1.07-3.70)\end{array}$ & 0.03 \\
\hline $\begin{array}{l}\text { Serum CA19-9 } \\
(\geqq 37 \mathrm{U} / \mathrm{ml} /<37 \mathrm{U} / \mathrm{ml})\end{array}$ & $\begin{array}{c}3.41 \\
(2.16-5.37)\end{array}$ & $<0.01$ & $\begin{array}{c}0.99 \\
(0.58-1.71)\end{array}$ & 0.98 \\
\hline $\begin{array}{l}\text { Exosomal miR-203 in serum } \\
\text { (high/low) }\end{array}$ & $\begin{array}{c}3.53 \\
(2.15-6.02)\end{array}$ & $<0.01$ & $\begin{array}{c}2.27 \\
(1.31-4.09)\end{array}$ & $<0.01$ \\
\hline
\end{tabular}

\section{DFS \\ (n=170)}

Histology

1.13

0.73

(Not well/Well)

(0.56-2.22)

Tumor size

$(\geqq 5 \mathrm{~cm} /<5 \mathrm{~cm})$

0.81

(0.39-1.62)

Depth of invasion

$(\geqq \mathrm{SS} / \leqq \mathrm{MP})$

1.47

(0.72-3.23)

Venous invasion

$$
2.98
$$

(1.41-7.07)

1.74
$(0.85-3.44)$

2.65

0.01

$(+/-)$

$(+/-)$

2.72

(1.38-5.59)

Lymph node metastasis

$(+/-)$
1.67

(0.83-3.50)
0.15

(Continued) 


\begin{tabular}{lcccc}
\hline Variables & \multicolumn{2}{c}{ Univariate analysis } & \multicolumn{2}{c}{ Multivariate analysis } \\
\cline { 2 - 5 } & $\begin{array}{c}\text { HR } \\
(\mathbf{9 5 \%} \text { CI } \mathbf{)}\end{array}$ & $\boldsymbol{P}$ & $\begin{array}{c}\text { HR } \\
\mathbf{( 9 5 \% ~ C I )}\end{array}$ & $\boldsymbol{P}$ \\
\hline $\begin{array}{l}\text { Serum CEA } \\
(\geqq 5.0 \mathrm{ng} / \mathrm{ml} /<5.0 \mathrm{ng} / \mathrm{ml})\end{array}$ & 2.27 & 0.02 & 2.14 & 0.03 \\
$\begin{array}{l}\text { Serum CA19-9 } \\
(1.15-4.48)\end{array}$ & & $(1.07-4.31)$ & \\
$\begin{array}{l}\text { Exosomal } \text { miR-203 in serum } \\
\text { (high/low) }\end{array}$ & 0.89 & 0.81 & & \\
\hline
\end{tabular}

${ }^{a} \mathrm{CI}$, confidence interval; ${ }^{\mathrm{b}} \mathrm{MP}$, muscularis propria; ${ }^{\mathrm{c}} \mathrm{SS}$, subserosa.

Table 2: Relationship between clinicopathological factors and exosomal miR-203 expression in serum in CRC

\begin{tabular}{|c|c|c|c|}
\hline Variables & $\begin{array}{l}\text { Low }(n=119) \\
\text { number }(\%)\end{array}$ & $\begin{array}{c}\text { High }(n=121) \\
\text { number }(\%)\end{array}$ & $P$ \\
\hline Sex & & & 0.81 \\
\hline Female & $47(39.5)$ & $46(38.0)$ & \\
\hline Male & $72(60.5)$ & $75(62.0)$ & \\
\hline Tumor size $(\mathrm{cm})$ & & & 0.59 \\
\hline$<5$ & $70(58.8)$ & $67(55.4)$ & \\
\hline$\geqq 5$ & $49(41.2)$ & $54(44.6)$ & \\
\hline Histology & & & 0.81 \\
\hline Well & $71(59.7)$ & $74(61.2)$ & \\
\hline Not Well & $48(40.3)$ & $47(38.8)$ & \\
\hline Depth of invasion & & & 0.11 \\
\hline$\leqq \mathrm{MP}^{\mathrm{a}}$ & $46(38.7)$ & $34(28.1)$ & \\
\hline$\geqq \mathrm{SS}^{\mathrm{b}}$ & $73(61.3)$ & 87 (71.9) & \\
\hline Venous invasion & & & 0.02 \\
\hline$(-)$ & $54(45.4)$ & $37(30.6)$ & \\
\hline$(+)$ & $65(54.6)$ & $84(69.4)$ & \\
\hline Lymphatic invasion & & & 0.06 \\
\hline$(-)$ & $82(68.9)$ & $69(57.0)$ & \\
\hline$(+)$ & $37(31.1)$ & $52(43.0)$ & \\
\hline Lymph node metastasis & & & $<0.01$ \\
\hline$(-)$ & $77(64.7)$ & $56(46.3)$ & \\
\hline$(+)$ & $42(35.3)$ & $65(53.7)$ & \\
\hline Distant metastasis & & & $<0.01$ \\
\hline$(-)$ & $97(81.5)$ & $78(64.5)$ & \\
\hline$(+)$ & $22(18.5)$ & $43(35.5)$ & \\
\hline
\end{tabular}




\begin{tabular}{|c|c|c|c|}
\hline Variables & $\begin{array}{l}\text { Low }(n=119) \\
\text { number }(\%)\end{array}$ & $\begin{array}{c}\text { High }(n=121) \\
\text { number }(\%)\end{array}$ & $P$ \\
\hline Liver metastasis & & & $<0.01$ \\
\hline$(-)$ & $115(96.6)$ & $79(65.3)$ & \\
\hline$(+)$ & $4(3.4)$ & $42(34.7)$ & \\
\hline Lung metastasis & & & 0.04 \\
\hline$(-)$ & $114(95.8)$ & $107(88.4)$ & \\
\hline$(+)$ & $5(4.2)$ & $14(11.6)$ & \\
\hline Peritoneal dissemination & & & 0.05 \\
\hline$(-)$ & $108(90.8)$ & $117(96.7)$ & \\
\hline$(+)$ & $11(9.2)$ & $4(3.3)$ & \\
\hline Others & & & 0.10 \\
\hline$(-)$ & $117(98.3)$ & $113(93.4)$ & \\
\hline$(+)$ & $2(1.7)$ & $8(6.6)$ & \\
\hline TNM Stage & & & $<0.01$ \\
\hline I, II & $68(57.1)$ & $37(30.6)$ & \\
\hline III, IV & $51(42.9)$ & $84(69.4)$ & \\
\hline
\end{tabular}

Correlation was analyzed by Fisher's exact test.

${ }^{a} \mathrm{MP}$, muscularis propria; ${ }^{\mathrm{b}} \mathrm{SS}$, subserosa.

$(P=0.05)$ and higher TNM stage $(P<0.01)$ (Table 2$).$ Tumor cells may acquire the ability to secret exosomal $m i R-203$ in serum during tumor progression.

These clinical data indicated that high expression of exosomal $m i R$-203 in serum was strongly associated with metastasis followed by poor prognosis, findings that would support our hypothesis that $m i R-203$ is a link between cancer and host cells in metastatic progression. However, the signaling role played by serum exosomal $m i R-203$ is not well understood.

\section{miR-203 released from $\mathrm{CRC}$ cells in vitro stimulated differentiation of monocytes to M2 macrophages}

TAMs are a critical component of the tumor microenvironment, and they affect tumor growth, immune suppression, and metastasis $[16,17]$. In particular, M2 macrophages, a subtype of TAMs, are thought to promote tumor development. Thus, miR-203 released from cancer cells may facilitate distant metastasis through directed differentiation of monocytes to M2 macrophages that constitute the premetastatic niche. In fact, immunohistochemical analysis revealed that many M2 macrophages (arginase 1-positive macrophages) infiltrated not only primary tumor tissues but also metastatic liver lesions in CRC (Figure 3A).
To pursue this finding, we conducted RTqPCR experiments to assess if miR-203 affected the differentiation of the monocytic cell line THP-1. Thus, we followed the expression of M1 markers (NOS2 and CXCL10) and M2 markers (CD163 and STAT3). First, coculture experiments using miR-203-transfected CRC cell lines (RKO and CaR-1) and THP-1 were performed in transwell culture plates allowing free exchange of culture medium. miR-203 was overexpressed in the miR-203transfected CRC cells (Supplementary Figure 1A). The expression of CD163 in THP-1 co-cultured with miR-203transfected RKO or CaR-1 was higher than with control cells (Figure 3B). Moreover, CXCL10 was downregulated in THP-1 co-cultured with miR-203-transfected CaR-1 (Figure 3B).

Next, exosomes from the supernatant of miR-203transfected cells were added to the culture medium of THP-1. The expression of exosomal miR-203 in the supernatant of miR-203-transfected cells was higher than from that of the control cells (Supplementary Figure 1A). Exosomes were incorporated into 27 of 46 THP-1 cells (Figure 3C). Finally, THP-1 was transfected with a miR-203 expression vector or empty vector. $m i R-203$ was overexpressed in miR-203-transfected THP-1 (Supplementary Figure 1B). The expression of the M2 marker in $m i R$-203-transfected THP-1 was higher than the control (Figure 3D). These observations suggest 
that miR-203 released from CRC cells could direct the differentiation of monocytes into M2 macrophages.

\section{miR-203 from circulating CRC cells promoted liver metastasis in a xenograft model}

To evaluate the metastatic potential of $m i R-203-$ transfected CRC cells, we conducted a liver metastasis assay using xenograft mice in which the cells were injected with or without THP-1 cells into the splenic vein (Figure 3E). Control cells alone did not produce liver nodules, whereas miR-203-transfected RKO cells generated nodules in 1 of 3 mice and miR-203-transfected RKO with THP-1 developed nodules in all 3 mice. The appearance of the livers of representative animals is shown in Figure 3E. Histological analysis showed that all liver nodules contained cancer cells, indicating there was a liver metastasis. These data indicate that $m i R-203$ from circulating CRC cells promoted liver metastasis.

\section{Overexpression of $m i R-203$ did not affect proliferation, invasive or migration capacity of cancer cells in vitro}

To examine the proliferation, invasive or migration potential of miR-203-transfected CRC cells, which are associated with metastatic potential, MTT proliferation assays and in vitro invasion or migration assays were performed using miR-203-transfected RKO and CaR-1 cells. There was no significant difference in either assay in comparisons of miR-203-transfected cells and the control cells (Supplementary Figure 2A, 2B, 2C). This observation supports our hypothesis that $m i R-203$ promotes metastasis by affecting host cells as described above.

\section{Clinical significance of $m i R-203$ expression in tumor tissues from CRC}

Our study demonstrated that exosomal miR-203 in serum could function as an oncogene in $\mathrm{CRC}$ by altering host cells and thereby promoting metastasis. However, there are several lines of evidence that $m i R-203$ can also work as a tumor suppressor in CRC. To determine the function of $m i R-203$ in tumor tissues, we examined the clinical significance of $m i R-203$ expression in CRC tissues using 2 independent datasets.

First, we investigated the clinical significance of miR-203 expression in tumor tissues using the The Cancer Genome Atlas (TCGA) database. The values ranged from 2.57 to 5.04 (median, 3.88). The cut-off value of $m i R-203$ expression was set at 4.12 as described in MATERIALS AND METHODS. The median expression levels of $m i R-203$ in the TNM stages were 3.94, 3.88, 3.88 and 3.94 , respectively (Figure 4A). Interestingly, the low $m i R$ 203 expression group showed poorer DFS than the high group $(P=0.02$, Figure 4B). Subgroup analyses for DFS by tumor stage are shown in Figure 4C. This trend was exhibited in all Stages except Stage I, but the statistical difference in DFS was noted among only patients with Stage II $(P=0.023)$. Furthermore, miR-203 expression was negatively correlated with a greater depth of invasion (T) $(P=0.005)$ (Figure 4D).

Next, we examined the clinical significance of pre-miR-203 expression in tumor tissues using Kyushu datasets. Pre-miR-203 was used in place of mature $m i R-203$ for RT-qPCR because only CRC tissue cDNA was available for the expression analysis in our institute and an analysis using CRC cell lines revealed that there was a high correlation of expression between mature $m i R-203$ and pre-miR-203 $\left(\mathrm{R}^{2}=0.69\right.$, Supplementary Figure $3 \mathrm{~A}, 3 \mathrm{~B})$. The values of pre-miR-203 expression in tumor tissues ranged from 0.094 to 18.8 (median, 0.791 ). The cut-off value of $m i R-203$ expression was set at 1.89 as described in MATERIALS AND METHODS. Supplementary Figure 3C showed that pre-miR-203 expression in tumor tissues was significantly higher than in normal tissues $(P=0.01)$, suggesting reactive expression of pre-miR-203 to suppress tumor development. Furthermore, similar results with that from the TCGA dataset were obtained, which showed that pre-miR-203 expression did not change with TNM stage (Supplementary Figure 3D) and the low pre-miR-203 expression group had poorer DFS than the high group $(P=0.03$, Supplementary Figure 3E). Multivariate analysis demonstrated that low expression of pre-miR-203 was an independent prognostic factor for DFS in CRC patients (Supplementary Table 1). Furthermore, pre-miR-203 expression was negatively correlated with a greater depth of invasion $(P=0.05$, Supplementary Table 2$)$.

Collectively, these 2 independent clinical datasets supported the observation that $m i R-203$ in tumor tissues may function as a tumor suppressor for CRC progression as reported elsewhere.

\section{DISCUSSION}

In this study, we identified $m i R-203$ as a link between tumor cells and monocytes through a bioinformatic analysis, and demonstrated that high expression of exosomal miR-203, a major form in circulation, was associated with high stage of tumor pathological aggressiveness and progression, including lymph node metastasis, venous invasion, distant metastasis and a higher TNM stage in CRC patients. Importantly, high exosomal miR-203 expression in serum was an independent poor prognostic factor, consistent with a recent similar study of circulating $m i R-203$ in CRC [18]. Moreover, we found that intravenous transfer of CRC cells that overexpressed miR-203 had a higher potential for liver metastasis in a xenograft model. Plus, $m i R-203$ promoted the differentiation of monocytes to M2 macrophages in vitro. These observations suggest 
A

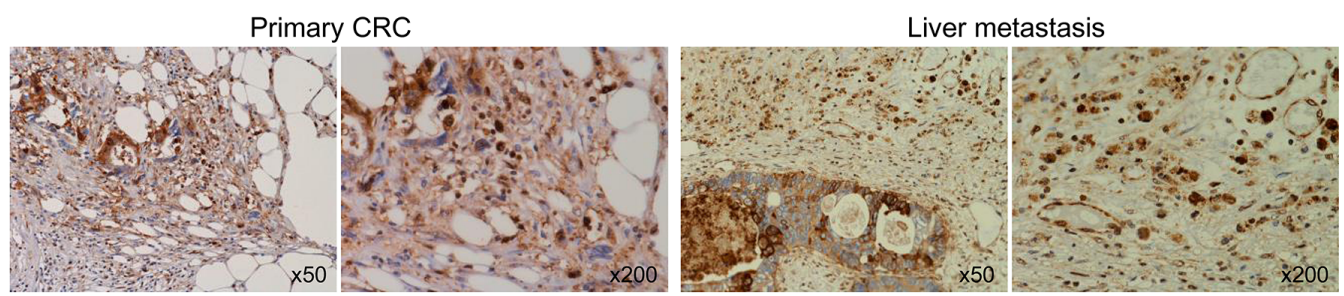

B
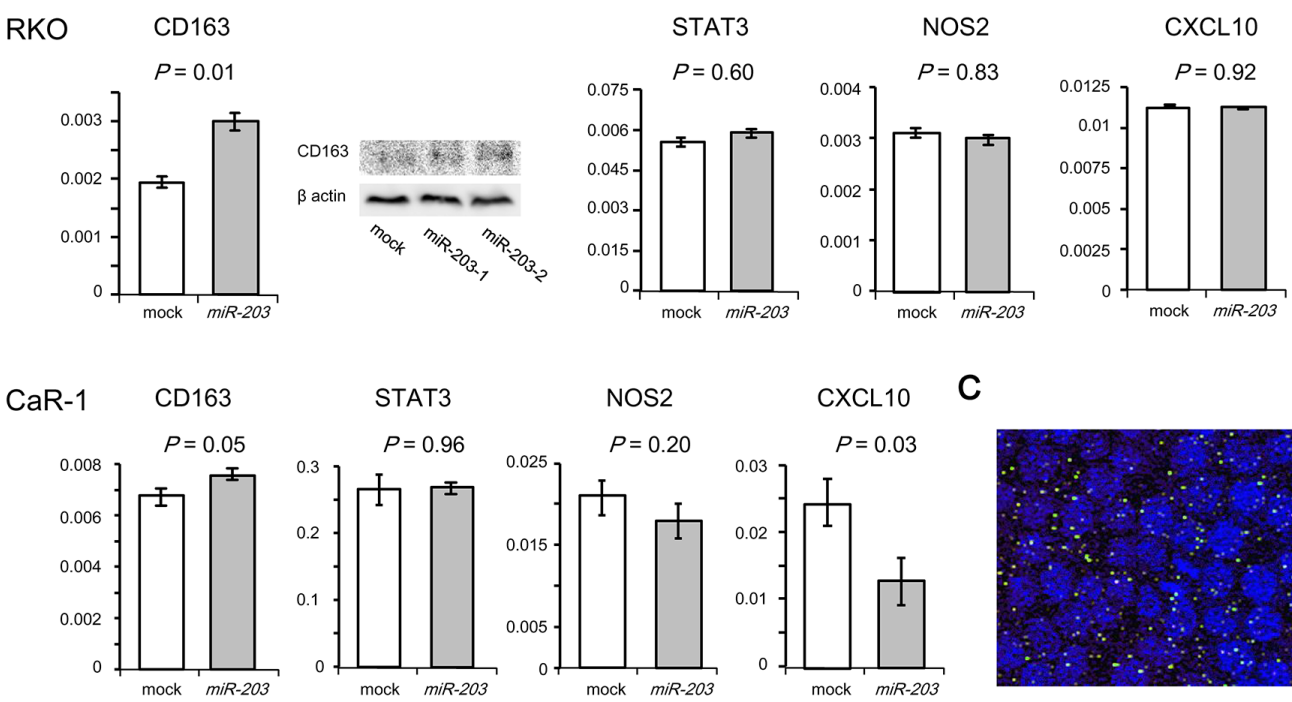

C

D
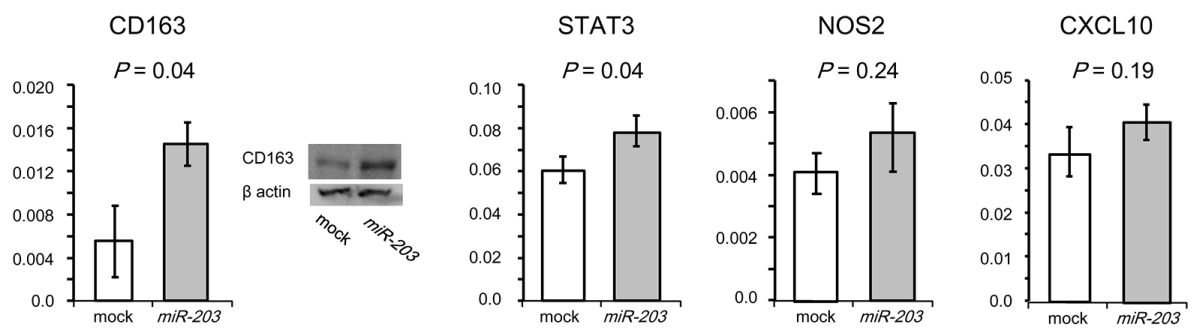

$\mathrm{E}$
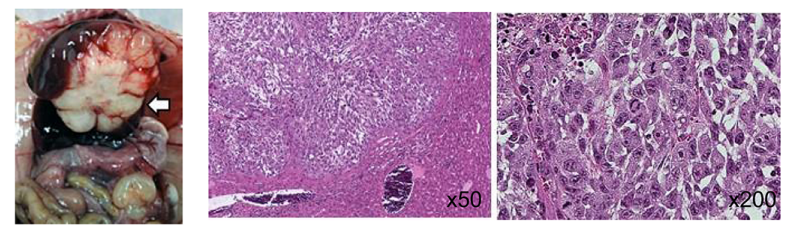

\begin{tabular}{|l|c|c|c|c|}
\hline \multicolumn{1}{c|}{ Cell source } & control & miR-203 & control+THP1 & miR-203+THP1 \\
\hline $\begin{array}{l}\text { number of mouse } \\
\text { with liver metastases } \\
\text { (total) }\end{array}$ & $0(3)$ & $1(3)$ & $1(3)$ & $3(3)$ \\
\hline \hline
\end{tabular}

Figure 3: Effect of miR-203 on the differentiation of monocytes to $\mathrm{M} 2$ macrophages and the metastatic potential of CRC cells. (A) Immunostaining for arginase 1 (M2 macrophage marker) in primary or liver metastatic lesion of CRC. Most of the macrophages and some of the cancer cells were positively stained. (B) Expression of M2 (CD163, STAT3) and M1 (NOS2, CXCL10) markers of THP-1s that were co-cultured with CRC cell lines (RKO and CaR-1). RT-qPCR, Western blot. (C) Labeling of exosomes with PKH67. Exosomes (green) were incorporated into THP-1s (blue). (D) Expression of M2 and M1 markers by THP-1 cells that were transfected with $m i R$-203. RT-qPCR, Western blot. (E) Xenograft liver metastatic mouse model. Animals were injected with $m i R-203$ transfected RKO cells or control RKO cells through the splenic vein with or without THP-1 cells. A representative image of the metastatic liver (upper left panel), histologic examination of liver metastases with H\&E staining (upper right panels) and the number of mice with liver metastasis (bottom panel). 
A

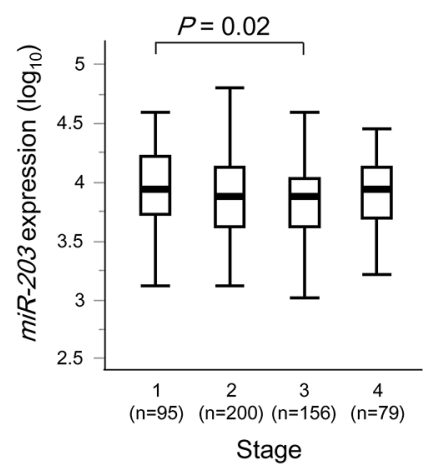

C

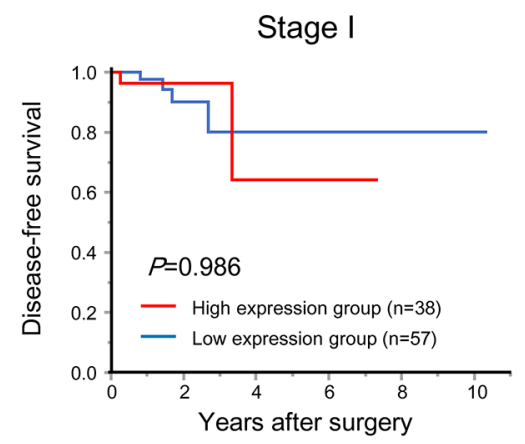

B

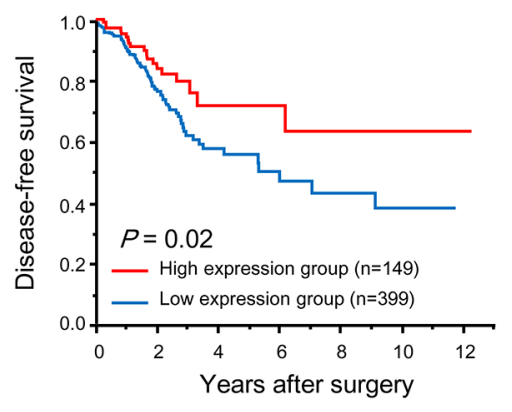

Stage II

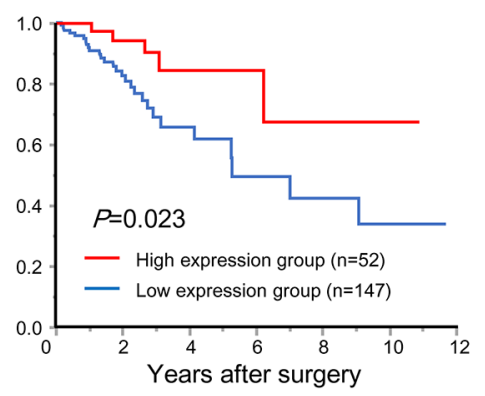

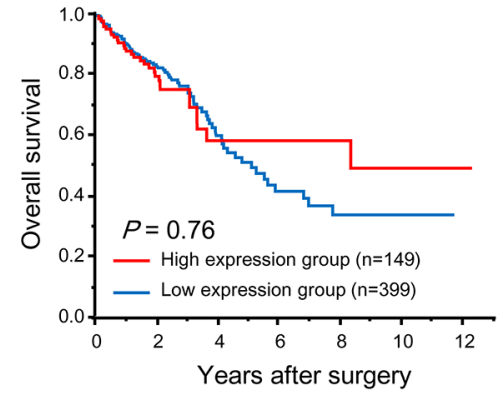

Stage III

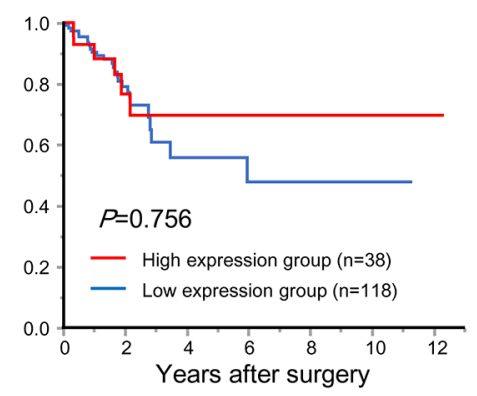

D
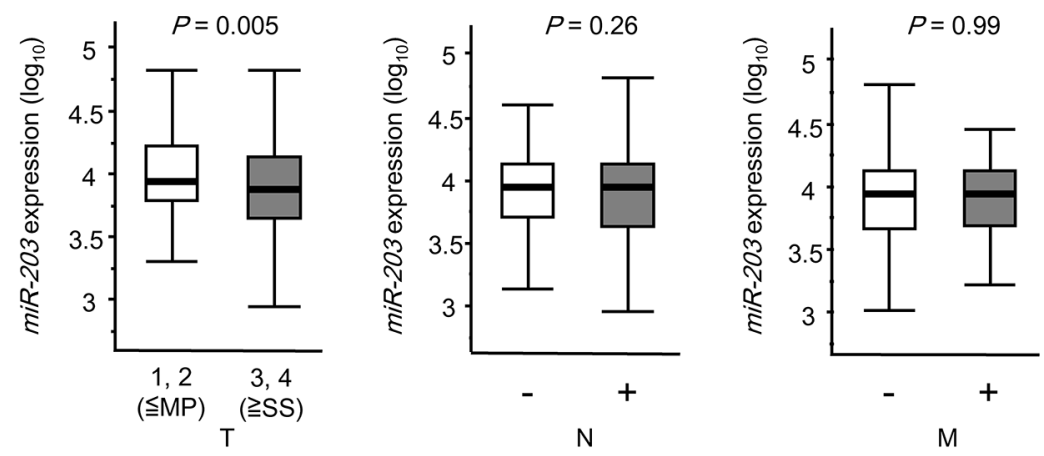

E

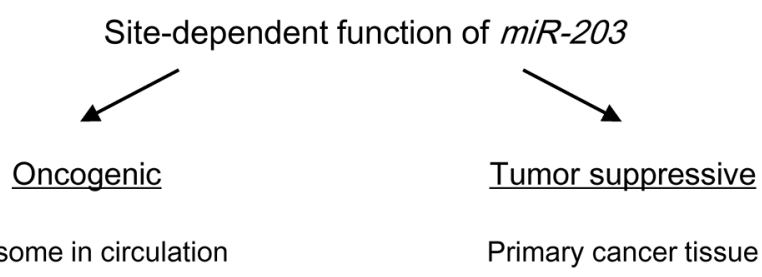

Site:

Exosome in circulation

Cancer cells?

Target cells:

Monocytes

Function:

Promote the differentiation

to M2 macrophage

Inhibit EMT?

Figure 4: Clinical significance of miR-203 expression in tumor tissues in CRC patients. (A) $m i R$-203 expression in different TNM stages of CRC from TCGA datasets. (B) Kaplan-Meier OS curves of CRC patients based on miR-203 expression in TCGA datasets. Left: DFS; Right: OS. (C) Subgroup analyses of DFS of the patients who underwent curative surgery according to tumor stage. (D) The relationship between $m i R-203$ expression and TNM factors in CRC patients in TCGA datasets. (E) Schematic depiction of site-dependent functions of $m i R-203$ in CRC progression. 
that circulating tumor-derived exosomal $m i R-203$ could facilitate distant metastasis by inducing host M2-TAMs to develop a premetastatic niche. Thus, exosomal miR-203 in serum may facilitate CRC progression by acting as an intercellular messenger between tumor and host cells. A further study using a genetically-engineered mouse model will be needed to validate this.

Recently, it was reported that tumor-derived exosomes containing miRs could initiate the formation of premetastatic niches by inducing host cells to promote metastasis in pancreatic and breast cancer [19-21]. Furthermore, an experimental mouse model showed that integrins in tumor-derived exosomes determined organotrophic metastasis [22]. Here, we have provided clinical evidence to support these observations, suggesting exosomes or their contents could be used for early diagnosis of metastasis and for targeted therapy in cancer treatment.

Interestingly, there is evidence that $m i R-203$ in tumor tissues acts as a tumor suppressor by promoting the mesenchymal to epithelial transition [23, 24] and inhibiting proliferation or invasion through direct targeting of certain oncogenes [25] [26-31], although the prognostic role in cancers remains elusive [32]. In fact, 2 independent datasets showed that the expression of $m i R-203$ in tumor tissues was inversely correlated with the depth of invasion and the high expression group had a better prognosis compared to the low expression group. Moreover, lower pre-miR-203 expression in tumor tissues was an independent poor prognostic factor in Kyushu dataset. Hence, our results demonstrate that miR-203 in tumor tissues works as a tumor suppressor whereas exosomal $m i R-203$ in serum acts as an oncogene by affecting host cells to promote metastasis. MiR-155 has also been shown experimentally to have conflicting functions in mouse breast cancer [33]. Recently, studies have focused on the contrasting roles of miRs in oncogenesis and tumor suppression $[32,34]$.

Here, we propose that tumor-derived miR has sitedependent functions that promote tumor development (Figure 4E). miRs may produce an overall net oncogenic or tumor suppressive effect [34]. Thus, miR localization should be considered for clinical cancer screening or anticancer therapy for targeting miR. Further examination of the functions of $\mathrm{miR}$ in various sites in cancer patients will be required to better understand its apparently conflicting functions in cancer progression.

The mechanism by which miR-203 promotes the differentiation of monocytes to M2 macrophages is unclear. Suppressor of cytokine signaling 3 (SOCS3), a target of $m i R-203$ [35], reportedly promotes activation of M1 macrophages and reduced expression of SOCS3 in macrophages resulted in the induction of M2 macrophages [36-39]. Therefore, tumor-derived exosomal miR-203 may reduce expression of SOCS3 followed by induction of M2 macrophages and inhibition of M1 macrophages. Further work is needed to clarify this.

In summary, we demonstrated that miR-203 constitutes a link between tumor and host cells and, furthermore, exosomal $m i R-203$ in serum could be a novel biomarker for predicting metastasis possibly via its promotion of monocyte differentiation to M2-TAMs and subsequent formation of premetastatic niches. Finally, we provide important clinical evidence that $m i R-203$ has dual functions in CRC progression.

Preventing metastasis by eliminating the formation of premetastatic niches through inhibition of intercellular signal miRs could be a new attractive approach for cancer treatment.

\section{MATERIALS AND METHODS}

\section{Clinical samples}

All clinical samples were obtained from CRC patients treated at Teikyo University Hospital or Kyushu University Beppu Hospital with written informed consent. This study was approved by each institutional review board, and the Ethics and Indications Committee. Clinicopathological factors and clinical stage were classified using the TNM system of classification. All data for the samples, including gender, tumor size and depth of invasion, lymphatic invasion, lymph node metastasis, vascular invasion, liver metastasis, peritoneal dissemination, distant metastasis, clinical stage, histological grade and serum tumor markers (CEA and CA19-9) were obtained from the clinical records. We treated patients in accordance with the Japanese Society of Cancer of the Colon and Rectum Guidelines for the Treatment of Colorectal Cancer. OS was defined as the time between the date of diagnosis and the date of death. DFS was defined as the length of time after surgical treatment for cancer during which the patient survived without a sign of recurrence.

We used a total of 240 serum samples from CRC patients treated at Teikyo University Hospital between 2005 and 2012 for extraction of exosomes. Forty-five corresponding matched CRC tissues were available. The median follow-up period was 54 months (range, 3-67 months). Patients treated with radiotherapy or chemotherapy prior to surgery were not included in the study. Blood samples were collected from patients before surgery.

Tumor tissues and paired normal tissues were obtained from $88 \mathrm{CRC}$ patients. Those patients underwent primary tumor resection at Kyushu University Beppu Hospital and affiliated hospitals between 1992 and 2007. The average overall survival time after resection was 4.03 years in all patients. Tumor recurrence was observed in 24 of 88 patients. 
Ten BM samples were obtained from CRC patients who underwent primary or metastatic tumor resection at Kyushu University Beppu Hospital in 2011. Among the 10 samples, 4 were from patients with liver metastases, and 6 were from those without metastases (Supplementary Table 3).

\section{Gene expression microarray analysis}

Cellular RNA expression levels were profiled using an Agilent DNA microarray system as described previously [40]. In brief, cyanine (Cy)-labeled cDNA was prepared using T7 linear amplification, after which it was fragmented and hybridized to an oligonucleotide microarray (Whole Human Genome $4 \times 44$ Agilent G4112F). Fluorescence intensities were obtained using an Agilent DNA microarray scanner and processed by quantile normalization [41]. The microarray data will be uploaded in Gene Expression Omnibus datasets (National Center for Biotechnology Information, Bethesda, MD, USA).

\section{Analysis of TCGA}

We obtained $m i R-203$ expression in tumor tissues, TNM classification and survival data from 548 CRC cases in TCGA from the Broad Institute's Firehose (http:// gdac.broadinstitute.org/runs/stddata_2016_01_28/data/ COADREAD/20160128/). The miR sequencing data were normalized with quantile normalization [41].

\section{GSEA}

GSEA analysis with miR target gene sets, which were defined in the collection of motif gene sets (C3) in the Molecular Signatures Database (MSigDB), was performed for gene expression data set from the metastatic CRC patient group and that from the non-metastatic CRC patient group, separately [42-44]. To make a pre-ranked gene list for each group as an input list for GSEA software, we examined gene expression differences between DTCs (CD14-/CD45-/EpCAM+ cells) and monocytes (CD14+ cells) with t-test for each gene within a group. We used the value $-\mathrm{I}_{\mathrm{i}} \log _{10} \mathrm{P}_{\mathrm{i}}$ as the metric for the $i$-th gene in each preranked gene list, where $P_{i}$ is the p-value of the t-test and $I_{i}$ is the indictor variable for which $I_{i}=1$ when the t-statistic $>0$ and $I_{i}=-1$ otherwise.

\section{Cell culture}

Ten different human CRC cell lines, CaR-1, RKO, Colo205, Colo320DM, DLD1, HCT116, Lovo, SW480, SW620 and HT29 and the human monocyte line THP1 were obtained from the Cell Resource Center for Biomedical Research Institute of Development, Aging and Cancer, Tohoku University. They were maintained in RPMI 1640 supplemented with $10 \%$ FBS at $37^{\circ} \mathrm{C}$ in a $5 \%$ humidified $\mathrm{CO}_{2}$ atmosphere.

To assess if the production of cellular factors such as exosomes from $m i R$-203-transfected cells affected the differentiation of THP-1, co-culture experiments were carried out in a transwell culture plate (Corning-Costar, Acton, MA, USA) allowing free exchange of culture medium and solutes. miR-203-transfected cells or the control and THP-1 were seeded in the lower and upper wells, respectively.

\section{Isolation of $\mathrm{BM}$ fractions}

$\mathrm{BM}$ was aspirated and separated into 3 fractions (CD14+, CD14-/CD45+, and CD14-/CD45-/EpCAM+) as previously described [14]. CD14, CD45 and EpCAM are monocyte, hematopoietic, and epithelial marker, respectively. In brief, BM aspirates were obtained from the sternum using a BM aspiration needle under general anesthesia before surgery. BM cells were separated into 3 fractions using a three-step automagnetic-activated cell separation system (MACS) by MACS Cell Separators (Miltenyi Biotec, Bergisch Gladbach, Germany). CD14+, CD14-/CD45+ and CD14-/CD45-/EpCAM+ cell fractions were collected using $C D 14, C D 45$, and EpCAM microbeads according to the manufacturer's instructions (Miltenyi Biotec), yielding monocytes, lymphocytes, and DTCs, respectively. Each fraction was mixed with IsogenLS (Nippon Gene, Toyama, Japan) and stored at $-80^{\circ} \mathrm{C}$.

\section{Isolation of exosomes}

Exosomes were isolated from serum or supernatant as described previously [13]. In brief, peripheral blood and $\mathrm{BM}$ were collected and centrifuged at 3000 r.p.m. for $10 \mathrm{~min}$ at $4^{\circ} \mathrm{C}$ to collect serum. Supernatants of cultured cells were collected after incubation with exosome-depleted FBS for 3 days. The supernatant was collected and centrifuged at $2000 \mathrm{~g}$ for $10 \mathrm{~min}$ at room temperature, and at $12000 \mathrm{~g}$ for $30 \mathrm{~min}$ followed by filtration through a $0.22-\mathrm{mm}$ filter to remove cell debris. Sera or supernatants $(1.0 \mathrm{~mL})$ intended for RT-qPCR were ultracentrifuged at $100000 \mathrm{~g}$ for $70 \mathrm{~min}$ at $4^{\circ} \mathrm{C}$. The pellets containing exosome were washed with PBS. The putative exosome fraction was measured for its protein content using a Quant-iTTM Protein Assay with a Qubit ${ }^{\circledR}$ 2.0 Fluorometer (Invitrogen). Nanoparticle tracking analysis was performed using the NanoSight LM10HS with a blue laser system (NanoSight, Amesbury, UK) on isolated exosomes diluted 500-fold with PBS for analysis.

\section{Extraction of total RNA}

Serum exosomes were extracted for total RNA using the miRNeasy serum/plasma kit (Qiagen, Venlo, Netherlands) according to the manufacturer's protocol. The RNA quality was assessed using an Agilent 2100 Bioanalyzer (Agilent Technologies, Santa Clara, Calif). Frozen tissue specimens or subconfluent cultured cell lines were homogenized, and total RNA was extracted using the modified acid-guanidinephenol-chloroform method with Isogen or Isogen-LS according to the manufacturer's instructions. 


\section{Reverse transcription-quantitative PCR (RT-qPCR)}

RT-qPCR assessments of $m i R-203, m i R-16$, and $R N U 6 B$ were performed as described previously [12]. In brief, $m i R-203, m i R-16$ and $R N U 6 B$-specific cDNAs were synthesized using gene-specific primer sets according to the TaqMan ${ }^{\circledR}$ Micro-RNA Reverse Transcription Kit protocol (Applied Biosystems, Foster City, Calif., USA). qPCR was performed using PCR LightCycler ${ }^{\circledR} 480$ Probes Master (Applied Biosystems). miR-203, miR-16 (as an internal control for vesicular $m i R-203$ [12]), and $R N U 6 B$ (as an internal control for intracellular $m i R-203$ ) were purchased from Applied Biosystems. Relative quantification of miR expression was calculated using the $2-\Delta \Delta \mathrm{Ct}$ method [45]. The raw data were presented as the relative quantity of target microRNA, normalized with respect to $m i R-16$ or $R N U 6 B$ and relative to a calibrator sample.

RT-qPCR assessments of pre-miR-203, CD163, STAT3, NOS2, CXCL10, and GAPDH were performed as previously described [46]. In brief, RT was performed with random hexamers using M-MLV reverse transcriptase (Invitrogen, Carlsbad, CA). qPCR was performed with LightCycler ${ }^{\circledR}$ FastStart DNA Master SYBR Green I (Roche Diagnostics). The raw data were presented as the relative quantity of target genes, normalized with respect to GAPDH. The primer sequences for RTPCR were as follows: pre-miR-203, forward 5'- TGG TCCTAAACATTTCACAA $-3^{\prime}$ and reverse 5'- TCCA GTGGTTCTTAACAGTTC -3'; CD163, forward 5'- CC ATGGGAGCGAAGAATC-3' and reverse 5'- CTCCAC GCACTCTTATTCTATCTTC-3'; STAT3 forward 5'- CC CTTGGATTGAGAGTCAAGA-3' and reverse 5'- AA GCGGCTATACTGCTGGTC-3'; NOS2, forward 5'- TTC CTTACGAGGCGAAGAAG-3' and reverse 5'- TCAGA GCGCTGACATCTCC-3'; CXCL10, forward 5'- CCCCAC GTTTTCTGAGACAT-3' and reverse 5'- TGGCAGTTT GATTCATGGTG-3' and GAPDH, forward, 5'-TTGGTAT CGTGGAAGGACTC-3' and reverse, 5'-AGTAGAGGC AGGGATGATGT-3'.

\section{Immunohistochemical staining}

Immunohistochemical studies of arginase 1 (M2 marker) were performed on specimens available from 10 CRC cases from Kyushu University using the avidinbiotin-peroxidase method (LSAB2 kit; Dako, Kyoto, Japan) on formalin-fixed, paraffin embedded tissues. All sections were counterstained with hematoxylin. The primary antibody against arginase 1 was used at dilutions of 1:1000. Rabbit polyclonal antibody to arginase 1 was purchased from Bioss Antibodies (Woburn, MA). Histological analysis was independently performed by an experienced research pathologist at Kyushu University.

\section{Western blot analysis}

Total protein was extracted from samples with RIPA buffer. Western blotting was performed as described previously [42]. Rabbit polyclonal antibody to $C D 163$ and mouse monoclonal antibodies to $\beta$-actin were purchased from Santa Cruz Biotechnology (Santa Cruz, CA). The dilutions were 1:500. The blots were developed with horseradish peroxidase-linked anti-rabbit or anti-mouse immunoglobulin (Promega, Inc., Madison, WI). Signals were detected using SuperSignal (Pierce, Inc., Rockford, IL).

\section{Labeling exosomes with PKH67}

Exosomes derived from RKO were isolated as described above and labeled using PKH67 Fluorescent Cell Linker kits (Sigma-Aldrich, St. Louis, MO) according to the manufacturer's instructions and described elsewhere [47]. To examine the uptake of exosomes into THP-1, the cells were plated in 8 -well chamber slides $\left(1 \times 10^{4}\right.$ cells/ well) using each medium. After $24 \mathrm{~h}$, the slides were washed three times in PBS, and each medium containing PKH67-labeled exosomes or a negative control sample was added to each well. Cells were cultured for $48 \mathrm{~h}$ at $37^{\circ} \mathrm{C}$ in an atmosphere of $5 \% \mathrm{CO}_{2}$. After incubation, the slides were washed three times with PBS, and $4 \%$ paraformaldehyde solution was then added to the slides. These were fixed for $10 \mathrm{~min}$ at room temperature. The slides were washed three times in PBS again. Nuclear staining was performed using a ProLong Gold antifade reagent with DAPI (Life Technologies) and the slide was covered with cover glass. Finally, the cells were visualized under a confocal laser scanning microscope LSM710 (Carl Zeiss, Oberkochen, Germany) under the same conditions. The green dots on THP-1 (blue cells) were regarded as exosomes incorporated into THP-1.

\section{Transfection assays and establishment of CRC cell lines stably transfected with pre-miR-203}

The backbone plasmid pcDNA6.2-GW/EmGFPmiR was from the Block-iT Pol II miR RNAi Expression Vector Kit (Invitrogen). The plasmids pcDNA6.2-GW/ EmGFP-pre-miR-203 (pCMV-pre-miR-203) containing pre-miR-203 and pcDNA6.2-GW/EmGFP-miR-neg (pCMV-N) containing an unrelated insert were constructed as described in the manual for the Block-iT Pol II miR RNAi Expression Vector Kit. The sequence of mature $m i R$-203 was GUGAAAUGUUUAGGACCACUAG (hsa$m i R-203 \mathrm{a}-3 \mathrm{p})$.

pCMV-pre-miR-203 and pCMV-mir-neg were transfected into the cell lines using Lipofectamine 3000 (Life Technologies, Inc., Tokyo, Japan) according to the manufacturer's instructions. Then, stably-transfected cells expressing mature miR-203 (miR-203-transfected cells) were selected with $\mathrm{G} 418(800 \mu \mathrm{g} / \mathrm{mL})$ treatment 
followed by sorting for GFP by MACS. A pCMV-mir-neg -transfected clone of each cell line was used for the control.

\section{MTT assay}

Cell proliferation was evaluated by performing MTT assays using a Cell Proliferation Kit 1 (Roche Applied Science, Penzberg, Germany) according to the manufacturer's instructions as described previously [40]. In brief, miR203-transfected cells and mock-transfected cells were seeded at 3,000 cells per well in triplicate 96well trays in $100 \mu \mathrm{L}$ medium. The color reaction was quantitated using an automatic plate reader, Immuno-Mini NJ-2300 (Nihon InterMed, Tokyo, Japan), at $570 \mathrm{~nm}$ with a reference filter of $650 \mathrm{~nm}$. Each independent experiment was carried out three times.

\section{In vitro invasion or migration assay}

Cell invasive or migration capacities were assessed using the BD BioCoat Tumor Invasion System, 24 Multiwell or the BD Falcon FluoroBlok 24 Multiwell Insert System (BD Bioscience) according to the manufacturer's instructions as described previously [40]. In brief, $m i R$-203-transfected cells and mock-transfected cells $\left(1.0 \times 10^{5}\right.$ cells/well $)$ were placed in the upper chamber, and the lower chamber was filled with $750 \mu \mathrm{L}$ of RPMI 1640 with $10 \%$ FBS as a chemoattractant, and incubated in a humidified atmosphere $\left(37^{\circ} \mathrm{C}\right.$ and $\left.5 \% \mathrm{CO}_{2}\right)$. After a $48 \mathrm{~h}$ incubation, the upper chamber was transferred into a second 24-well plate containing $500 \mu \mathrm{L}$ of $4 \mu \mathrm{g} /$ $\mathrm{mL}$ calcein AM in HBSS in each well, and the plates were incubated for an additional $1 \mathrm{~h}\left(37^{\circ} \mathrm{C}\right.$ and $\left.5 \% \mathrm{CO}_{2}\right)$. Invasive cells that migrated through the membrane were evaluated in a fluorescence plate reader at excitation/ emission wavelengths of $485 / 535 \mathrm{~nm}$. Invasiveness was measured as the percentage of fluorescence of an invasive fibrosarcoma cell line (HT-1080) that served as a control. Each independent experiment was performed three times.

\section{Liver metastasis studies in a xenograft mouse model}

To analyze the role of $m i R-203$ in tumor metastasis, 6- to 8-week-old BALB/c nu/nu female mice were injected intrasplenically with $1 \times 10^{6} \mathrm{miR}$-203-transfected or the control RKO cells suspended in $100 \mu \mathrm{L}$ PBS. Three weeks later, the mice were euthanized and the livers were analyzed for metastatic lesions by counting or measuring liver weights. The number of liver nodules that were larger than $5 \mathrm{~mm}$ in diameter was also determined as metastases. All of the animal studies were approved by the ethics committee of Kyushu University and all animal procedures were performed in compliance with the Guidelines for the Care and Use of Experimental Animals established by the Committee for Animal Experimentation of Kyushu
University; these guidelines conform to the ethical standards required by Japanese law and also comply with the guidelines for the use of experimental animals in Japan.

\section{Statistical analysis}

For clinical analysis, cases were divided into two groups using the minimum $\mathrm{P}$ value approach based on the miR-203 expression level, which is a comprehensive method to identify the optimal risk separation cutoff point in continuous gene expression measurements for survival analysis in multiple datasets [48]. Associations between the variables were tested with the Mann-Whitney U test or Fisher's exact test. The degree of linearity was estimated by Pearson's correlation co-efficient. Survival curves were drawn according to the Kaplan-Meier method and survival analysis was carried out by the log-rank test when two curves were being compared. Cox proportional hazards regression was used to determine univariate and multivariate hazard ratios for OS and DFS. A two-sided $P \leqq 0.05$ was deemed statistically significant. Statistical analyses were performed using JMP Pro 12 software (SAS Institute, Cary, N.C., USA).

\section{ACKNOWLEDGMENTS}

We thank M. Oshiumi, M. Uto, K. Oda, M. Kasagi, S. Sakuma, N. Mishima and T. Kawano for their technical assistance, and Dr. Tyler Lahusen for English proofreading.

\section{CONFLICTS OF INTEREST}

The authors declare no conflicts of interest.

\section{FUNDING}

This work was supported in part by the following grants and foundations: Japan Society for the Promotion of Science (JSPS) Grant-in-Aid for Science Research (Grant Numbers 16K07177, 16K10543, 16K10397, 16K19197, 16K19107, 16H01576, 26461980 and 26293303); OITA Cancer Research Foundation; Daiwa Securities Health Foundation; Grant-inAid for Scientific Research on Innovative Areas (15H0912); Priority Issue on Post-K computer (hp170227) (hp170227, hp160219); JSPS KAKENHI (15H05707).

\section{REFERENCES}

1. Jemal A, Bray F, Center MM, Ferlay J, Ward E, Forman D. Global cancer statistics. CA Cancer J Clin. 2011; 61:69-90.

2. Wood LD, Parsons DW, Jones S, Lin J, Sjoblom T, Leary RJ, Shen D, Boca SM, Barber T, Ptak J, Silliman N, Szabo $\mathrm{S}$, Dezso Z, et al. The genomic landscapes of human breast and colorectal cancers. Science. 2007; 318:1108-1113. 
3. Paget $\mathrm{S}$. The distribution of secondary growths in cancer of the breast. 1889. Cancer Metastasis Rev. 1989; 8:98-101.

4. Wilson C, Holen I, Coleman RE. Seed, soil and secreted hormones: potential interactions of breast cancer cells with their endocrine/paracrine microenvironment and implications for treatment with bisphosphonates. Cancer Treat Rev. 2012; 38:877-889.

5. Sceneay J, Smyth MJ, Moller A. The pre-metastatic niche: finding common ground. Cancer Metastasis Rev. 2013; 32:449-464.

6. Yumimoto K, Akiyoshi S, Ueo H, Sagara Y, Onoyama I, Ueo H, Ohno S, Mori M, Mimori K, Nakayama KI. F-box protein FBXW7 inhibits cancer metastasis in a non-cellautonomous manner. J Clin Invest. 2015; 125:621-635.

7. Gallo A, Tandon M, Alevizos I, Illei GG. The majority of microRNAs detectable in serum and saliva is concentrated in exosomes. PLoS One. 2012; 7:e30679.

8. Qi F, He T, Jia L, Song N, Guo L, Ma X, Wang C, Xu M, $\mathrm{Fu}$ Y, Li L, Luo Y. The miR-30 family inhibits pulmonary vascular hyperpermeability in the premetastatic phase by direct targeting of Skp2. Clin Cancer Res. 2015; 21:3071-3080.

9. Zomer A, Maynard C, Verweij FJ, Kamermans A, Schafer R, Beerling E, Schiffelers RM, de Wit E, Berenguer J, Ellenbroek SI, Wurdinger T, Pegtel DM, van Rheenen J. In Vivo imaging reveals extracellular vesicle-mediated phenocopying of metastatic behavior. Cell. 2015; 161:1046-1057.

10. Tarver JE, Sperling EA, Nailor A, Heimberg AM, Robinson JM, King BL, Pisani D, Donoghue PC, Peterson KJ. miRNAs: small genes with big potential in metazoan phylogenetics. Mol Biol Evol. 2013; 30:2369-2382.

11. Akiyoshi S, Fukagawa T, Ueo H, Ishibashi M, Takahashi Y, Fabbri M, Sasako M, Maehara Y, Mimori K, Mori M. Clinical significance of miR-144-ZFX axis in disseminated tumour cells in bone marrow in gastric cancer cases. Br J Cancer. 2012; 107:1345-1353.

12. Matsumura $T$, Sugimachi K, Iinuma H, Takahashi $Y$, Kurashige J, Sawada G, Ueda M, Uchi R, Ueo H, Takano Y, Shinden Y, Eguchi H, Yamamoto H, et al. Exosomal microRNA in serum is a novel biomarker of recurrence in human colorectal cancer. Br J Cancer. 2015; 113:275-281.

13. Sugimachi K, Matsumura $T$, Hirata H, Uchi R, Ueda M, Ueo H, Shinden Y, Iguchi T, Eguchi H, Shirabe K, Ochiya T, Maehara Y, Mimori K. Identification of a bona fide microRNA biomarker in serum exosomes that predicts hepatocellular carcinoma recurrence after liver transplantation. Br J Cancer. 2015; 112:532-538.

14. Sugimachi K, Sakimura S, Tomokuni A, Uchi R, Hirata H, Komatsu H, Shinden Y, Iguchi T, Eguchi H, Masuda T, Morita K, Shirabe K, Eguchi H, et al. Identification of recurrence-related microRNAs from bone marrow in hepatocellular carcinoma patients. J Clin Med. 2015; 4:1600-1611.
15. Pap E, Pallinger E, Pasztoi M, Falus A. Highlights of a new type of intercellular communication: microvesicle-based information transfer. Inflamm Res. 2009; 58:1-8.

16. Ostuni R, Kratochvill F, Murray PJ, Natoli G. Macrophages and cancer: from mechanisms to therapeutic implications. Trends Immunol. 2015; 36:229-239.

17. Jinushi M, Komohara Y. Tumor-associated macrophages as an emerging target against tumors: creating a new path from bench to bedside. Biochim Biophys Acta. 2015; 1855:123-130.

18. Hur K, Toiyama Y, Okugawa Y, Ide S, Imaoka H, Boland CR, Goel A. Circulating microRNA-203 predicts prognosis and metastasis in human colorectal cancer. Gut. 2017; 66:654-665.

19. Fong MY, Zhou W, Liu L, Alontaga AY, Chandra M, Ashby J, Chow A, O'Connor ST, Li S, Chin AR, Somlo G, Palomares M, Li Z, et al. Breast-cancer-secreted miR-122 reprograms glucose metabolism in premetastatic niche to promote metastasis. Nat Cell Biol. 2015; 17:183-194.

20. Costa-Silva B, Aiello NM, Ocean AJ, Singh S, Zhang H, Thakur BK, Becker A, Hoshino A, Mark MT, Molina H, Xiang J, Zhang T, Theilen TM, et al. Pancreatic cancer exosomes initiate pre-metastatic niche formation in the liver. Nat Cell Biol. 2015; 17:816-826.

21. Rana S, Malinowska K, Zoller M. Exosomal tumor microRNA modulates premetastatic organ cells. Neoplasia. 2013; 15:281-295.

22. Hoshino A, Costa-Silva B, Shen TL, Rodrigues G, Hashimoto A, Tesic Mark M, Molina H, Kohsaka S, Di Giannatale A, Ceder S, Singh S, Williams C, Soplop N, et al. Tumour exosome integrins determine organotrophic metastasis. Nature. 2015; 527:329-335.

23. Moes M, Le Bechec A, Crespo I, Laurini C, Halavatyi A, Vetter G, Del Sol A, Friederich E. A novel network integrating a miRNA-203/SNAI1 feedback loop which regulates epithelial to mesenchymal transition. PLoS One. 2012; 7:e35440.

24. DeCastro AJ, Dunphy KA, Hutchinson J, Balboni AL, Cherukuri P, Jerry DJ, DiRenzo J. MiR203 mediates subversion of stem cell properties during mammary epithelial differentiation via repression of DeltaNP63alpha and promotes mesenchymal-to-epithelial transition. Cell Death Dis. 2013; 4:e514.

25. Deng B, Wang B, Fang J, Zhu X, Cao Z, Lin Q, Zhou L, Sun X. MiRNA-203 suppresses cell proliferation, migration and invasion in colorectal cancer via targeting of EIF5A2. Sci Rep. 2016; 6:28301.

26. Viticchie G, Lena AM, Latina A, Formosa A, Gregersen LH, Lund AH, Bernardini S, Mauriello A, Miano R, Spagnoli LG, Knight RA, Candi E, Melino G. MiR-203 controls proliferation, migration and invasive potential of prostate cancer cell lines. Cell Cycle. 2011; 10:1121-1131.

27. Wang C, Zheng X, Shen C, Shi Y. MicroRNA-203 suppresses cell proliferation and migration by targeting 
BIRC5 and LASP1 in human triple-negative breast cancer cells. J Exp Clin Cancer Res. 2012; 31:58.

28. Wang C, Wang X, Liang H, Wang T, Yan X, Cao M, Wang N, Zhang S, Zen K, Zhang C, Chen X. miR-203 inhibits cell proliferation and migration of lung cancer cells by targeting PKCalpha. PLoS One. 2013; 8:e73985.

29. Wang N, Liang H, Zhou Y, Wang C, Zhang S, Pan Y, Wang Y, Yan X, Zhang J, Zhang CY, Zen K, Li D, Chen $X$. miR-203 suppresses the proliferation and migration and promotes the apoptosis of lung cancer cells by targeting SRC. PLoS One. 2014; 9:e105570.

30. Liang M, Shi B, Liu J, He L, Yi G, Zhou L, Yu G, Zhou $\mathrm{X}$. Downregulation of miR203 induces overexpression of PIK3CA and predicts poor prognosis of gastric cancer patients. Drug Des Devel Ther. 2015; 9:3607-3616.

31. Obayashi M, Yoshida M, Tsunematsu T, Ogawa I, Sasahira $\mathrm{T}$, Kuniyasu $\mathrm{H}$, Imoto I, Abiko $\mathrm{Y}, \mathrm{Xu} \mathrm{D}$, Fukunaga S, Tahara H, Kudo Y, Nagao T, et al. microRNA-203 suppresses invasion and epithelial-mesenchymal transition induction via targeting NUAK1 in head and neck cancer. Oncotarget. 2016; 7:8223-8239. https://doi.org/10.18632/ oncotarget.6972.

32. Liang Y, Yang W, Zhu Y, Yuan Y. Prognostic role of microRNA-203 in various carcinomas: evidence from a meta-analysis involving 13 studies. Springerplus. 2016; 5:1538.

33. Xiang $X$, Zhuang $X$, Ju S, Zhang S, Jiang H, Mu J, Zhang L, Miller D, Grizzle W, Zhang HG. miR-155 promotes macroscopic tumor formation yet inhibits tumor dissemination from mammary fat pads to the lung by preventing EMT. Oncogene. 2011; 30:3440-3453.

34. Svoronos AA, Engelman DM, Slack FJ. OncomiR or tumor suppressor? The duplicity of microRNAs in cancer. Cancer Res. 2016; 76:3666-3670.

35. Ru P, Steele R, Hsueh EC, Ray RB. Anti-miR-203 upregulates SOCS3 expression in breast cancer cells and enhances cisplatin chemosensitivity. Genes Cancer. 2011; 2:720-727.

36. Hiwatashi K, Tamiya T, Hasegawa E, Fukaya T, Hashimoto M, Kakoi K, Kashiwagi I, Kimura A, Inoue N, Morita R, Yasukawa H, Yoshimura A. Suppression of SOCS3 in macrophages prevents cancer metastasis by modifying macrophage phase and MCP2/CCL8 induction. Cancer Lett. 2011; 308:172-180.

37. Arnold CE, Whyte CS, Gordon P, Barker RN, Rees AJ, Wilson HM. A critical role for suppressor of cytokine signalling 3 in promoting M1 macrophage activation and function in vitro and in vivo. Immunology. 2014; 141:96-110.
38. Wilson HM. SOCS proteins in macrophage polarization and function. Front Immunol. 2014; 5:357.

39. Liu Y, Stewart KN, Bishop E, Marek CJ, Kluth DC, Rees AJ, Wilson HM. Unique expression of suppressor of cytokine signaling 3 is essential for classical macrophage activation in rodents in vitro and in vivo. J Immunol. 2008; 180:6270-6278.

40. Kurashige J, Hasegawa T, Niida A, Sugimachi K, Deng N, Mima K, Uchi R, Sawada G, Takahashi Y, Eguchi H, Inomata M, Kitano S, Fukagawa T, et al. Integrated molecular profiling of human gastric cancer identifies DDR2 as a potential regulator of peritoneal dissemination. Sci Rep. 2016; 6:22371.

41. Garmire LX, Subramaniam S. Evaluation of normalization methods in mammalian microRNA-Seq data. RNA. 2012; 18:1279-1288.

42. Hirata H, Sugimachi K, Komatsu H, Ueda M, Masuda T, Uchi R, Sakimura S, Nambara S, Saito T, Shinden Y, Iguchi T, Eguchi H, Ito S, et al. Decreased expression of fructose1,6-bisphosphatase associates with glucose metabolism and tumor progression in hepatocellular carcinoma. Cancer Res. 2016; 76:3265-3276.

43. Subramanian A, Tamayo P, Mootha VK, Mukherjee S, Ebert BL, Gillette MA, Paulovich A, Pomeroy SL, Golub TR, Lander ES, Mesirov JP. Gene set enrichment analysis: a knowledge-based approach for interpreting genomewide expression profiles. Proc Natl Acad Sci U S A. 2005; 102:15545-15550.

44. Mootha VK, Lindgren CM, Eriksson KF, Subramanian A, Sihag S, Lehar J, Puigserver P, Carlsson E, Ridderstrale M, Laurila E, Houstis N, Daly MJ, Patterson N, et al. PGC-1alpha-responsive genes involved in oxidative phosphorylation are coordinately downregulated in human diabetes. Nat Genet. 2003; 34:267-273.

45. Fukushima Y, Iinuma H, Tsukamoto M, Matsuda K, Hashiguchi Y. Clinical significance of microRNA-21 as a biomarker in each Dukes' stage of colorectal cancer. Oncol Rep. 2015; 33:573-582.

46. Masuda TA, Inoue H, Nishida K, Sonoda H, Yoshikawa Y, Kakeji Y, Utsunomiya T, Mori M. Cyclin-dependent kinase 1 gene expression is associated with poor prognosis in gastric carcinoma. Clin Cancer Res. 2003; 9:5693-5698.

47. Chiba M, Kimura M, Asari S. Exosomes secreted from human colorectal cancer cell lines contain mRNAs, microRNAs and natural antisense RNAs, that can transfer into the human hepatoma HepG2 and lung cancer A549 cell lines. Oncol Rep. 2012; 28:1551-1558.

48. Mizuno H, Kitada K, Nakai K, Sarai A. PrognoScan: a new database for meta-analysis of the prognostic value of genes. BMC Med Genomics. 2009; 2:18. 